\title{
Anacronismos: Mário de Andrade y Guimarães Rosa en el Contexto de la Novela Hispanoamericana*
}

I.

Todos sabemos que Macunaíma y Grande Sertão: Veredas fueron escritas en portugués y en el Brasil, y que fueron publicadas (en São Pauloy Río de Janeiro, respectivamente) por primera vez en ediciones brasileñas. También sabemos que el lector español no dispone aún de una traducción completa de Macunaíma al castellano (aunque ya hay una pronta) y que la edicón española de Grande Sertão: Veredas salió unos diez años después de la original. Esos datos son de dominio público y están al alcance de todos. Los estudiosos de la literatura brasileña los conocen de memoria. Para ellos (para todos) no hay duda de que el contexto cultural en que se han leído y deben leerse estas obras es uno solo: el brasileño. De acuerdo.

Pero ¿qué pasaría si, por un momento, nos imagináramos que ambas obras fueron escritas en español y publicadas en un país de América Latina que no existe pero que si existiera se parecería sospechosamente al verdadero Brasil? $\mathrm{O}$, dicho de otro modo: ¿ qué pasaría si Macunaíma estuviera originariamente escrita en la lengua tal vez primera de Wenceslao Pietro Pietra (al fin y al cabo, el gigante antropófago de esa novela venía del Perú), y qué pasaría asimismo si la gran novela de Guimarães Rosa se llamase: Gran pampa: caminitos?

No quiero proponer un juego inútil. Quierosugerir modestamente otra cosa: ¿por qué no insertar Macunaíma y Grande Sertão: Veredas en el contexto de la novela hispanoamericana y ver qué pasa? Al fin y al cabo, ambos libros fueron escritos y publicados en América Latina por escritores que no sólo leían los mismos autores europeos que leían los hispanoamericanos sino que (más importante aún) estaban insertados en los mismos contextos culturales, en la misma realidad americana general, en dos lenguas cuyas semejanzas (y diferencias) son tantalizadoras. Lo único que separaba (pero ya casi no separa) los textos de Guimarães Rosa y Mário de Andrade de los de sus colegas hispanoamericanos era una compartamentalización de la cultura latinoamericana que sólo sirve a los intereses (no precisamente culturales) de los grandes imperios.

* La presente es una versión algo más desarrollada de la conferencia sobre el mismo tëma dictada en la Universidad de São Paulo en setiembre 26, 1975. 
De modo que leer Macunaíma y Grande Sertão: Veredas en el contexto de la novela hispanoamericana no es privarlas del contexto brasileño (operación no sólo ridícula sino imposible): es enriquecer ese contexto al ampliarlo para abarcar una literatura paralela y tan cercana. Pero es, también, enriquecer el contexto de la literatura hispanoamericana por la operación, en apariencia mágica pero tan común, de situar esas obras en su centro. El juego (que no es tal, cuando se piensa bien) consiste pues en leer ambas novelas anacrónicamente--como proponía Pierre Menard, o tal vez sólo su inventor, Jorge Luis Borges.

II.

Si Macunaíma hubiese sido publicada en español en 1928, en un Brasil en que todos hablasen español, en un continente unificado del todo por la lengua, ¿con qué libros habría sido comparadō? Ese año de 1928 hacía sólo dos que José Eustasio Rivera había publicado en Colombia La vorágine, la gran novela de la selva que también se sitúa en la cuenca amazónica. En Buenos Aires, Ricardo Güiraldes había publicado, también en 1926, Don Segundo Sombra, elegía intimista de la muerte de un prototipo gauchesco, cuidadosamente disfrazada de novela. Un año después de Macunaíma, aparecería en España la novela más famosa del escritor venezolano, Rómulo Gallegos: Doña Bárbara, increíble supervivencia del "romance" del siglo XVIII en las letras contemporáneas. Estos libros marcaban entonces el punto más alto de la novela hispanoamericana. ¿Qué papel haría entre ellos Macunaima?

Es obvio que un papel extraño, curioso, tan escandaloso como el que produjo en el contexto brasileño en que por mucho tiempo se la tomó por un chiste, una locura, por un disparate hasta que Cavalcanti Proença primero, y Haroldo de Campos después, demostraron minuciosamente que no sólo estaba rigurosamente documentada sino (lo que es más importante) que estaba brillantemente estructurada. En el contexto de la novela hispanoamericana, Macunaíma habría hecho explotar ya en 1928 la concepción aún demasiado apegada al realismo del siglo XIX de los que fueron entonces llamados "novelistas de la tierra". En tanto que Rivera, Guiraldes y Gallegos se sometían a contar una historia, a crear situaciones verosímiles, a desarrollar un paisaje, y una aventura coherentes, Mário de Andrade saltaba por encima de las convenciones del realismo y se instalaba en pleno mito. Mientras Rivera debía apelar a la grandilocuencia romántica del discurso y hasta a una forma demagógica de la proosopopeya para hacer vivir la selva amazóniza, Mário de Andrade la daba por sentada, la dramatizaba en su vocabulario, la hacía patente en la parodia de sus mitos. Güiraldes buscaba la exaltación elegíaca por el camino de una épica literaria que convertía un oficio duro pero rutinario (el de los troperos) en una permanente hipérbole, Más sabio, Mário de Andrade apelaba a la parodia y a la carnavalización para sugerir las dimensiones desaforadas de esa naturaleza y de ese mundo en que tiene sus raíces el Brasil. El enfoque de 
Gallegos volvía a Sarmiento para definir una dicotomía (civilización o barbarie) que ya era anacrónica en este siglo. y sólo conseguía escapar de las limitaciones de su enfoque realista y su cosmovisión positivista al reinventar (tal vez inocentemente) el género romance en que los personajes son arquetípicos, la acción simbólica y un aura de irrealidad poética lo contamina todo. El mismo efecto lo conseguía Mário de Andrade por el humor popular injertado en la ironía más sofisticada posible.

Una última paradoja: tanto Rivera como Güiraldes y Gallegos, se instalaban en el realismo para dar a sus novelas una dimensión documental. Los tres querían rescatar una imagen de esos mundos americanos en que la naturaleza devora al hombre y en que sólo la ejemplaridad del prototipo (Santos Luzardo o Segundo Sombra) puede aportar una solución. Mário de Andrade usaba el mito, la parodia, la carnavalizacíon para restituir al Brasil una imagen deformada pero real: la imagen de una vitalidad, de un apetito canibalesco, de un deseo inagotable. El intento de Mário de Andrade resultaba no menos sino más real que los esfuerzos (demasiado miméticos) de sus compañeros de continente. Al prescindir del realismo, Mário de Andrade estaba dándonos una lección: el realismo no es la realidad sino una forma literaria, una convención. Y lo que le interesaba a Mário de Andrade no era imitar la realidad sino descodificarla.

\section{III.}

Otros son libros de la literatura hispanoamericana a los que es posible aproximar Macunaíma. Esos libros no existían aún en 1928 peroempezaron a existir unos años después. El más conocido es, tal vez, Hombres de maíz, de Miguel Angel Asturias, que se publicó por primera vez en 1949. En esta novela, el narrador guatemalteco presenta el conflicto entre un sector de la población indígena que quiere seguir cultivando el maíz sólo para alimentarse porque el maíz tiene un sentido religioso para ellos (los hombres fueron hechos de maíz por los dioses), y otro sector ya occidentalizado que quiere cultivar maíz para venderlo. En el primer grupo predominan las raíces indígenas y una cosmovisión mítica que proviene de la cultura maya; en el segundo, el desarrollismo que es signo de la sociedad latinoamericana actual. Pero si el resumen hace pensar que se trata de una novela del realismo socialista (como las que infortunadamente practicó en parte Asturias en su posterior trilogía bananera), la narración misma de Hombres de maíz contrasta la visión de los indígenas (maravillosa, mágica) con la de los desarrollados. Los límites entre la convención realista y la mágica se borran. Los personajes son simultáneamente campesinos guatemaltecos y animales totémicos o piedras sagradas. Como en Macunaíma, el mito es más fuerte que la mimesis realista.

Las distancias entre ambas obras son, sin embargo, abismales. No hay en Macunaima el propósito pedagógico de Asturias. Le falta a Hombres de maiz el sentido de la parodia, de carnavalización de la realidad ficticia que 
hace de Macunaima un libro tan delicioso. Y sin embargo, los dos libros se han propuesto algo similar: el rescate de una mitología y de una cosmovisión que aunque aparentemente destruída por la cultura occidental sigue viva en las entrelíneas del texto de la realidad latinoamericana. Los une otra cosa: tanto Asturias como Mário de Andrade llegaron a descodificar los mitos originales de sus respectivos países a través de monumentos de la erudición europea. Asturias descubrió las ruinas mayas no en Guatemala sino en el British Museum, y estudió la cultura de su propio país en los cursos de la Sorbonne que dictaba el profesor Raynaud. Hasta su traducción en español del Popol Vuh (el libro sagrado de los mayas) está hecha del francés. Mário de Andrade, a su vez, encontró en un eruditísimo estudio de los mitos amazónicos, organizado por el profesor alemán Koch-Grünberg, la materia prima de los mitos que recrearía en Macunaíma. Pero si los dos traen de la cultura europea la erudición necesaria, los dos llevan en su lengua y en su propia sangre ese mestizaje fundamental que caracteriza desde los primeros siglos al hombre y la cultura americanos.

Otro mestizo, Severo Sarduy, en que lo blanco, lo negro y lo amarillo se dan hermosamente integrados, habría de escribiry publicar en 1966 un libro que es para Cuba lo que Macunaíma es para el Brasil. Se llama De donde son los cantantes, y en tres momentos narrativos expone las raíces culturales de la isla. Un primer episodio que se centra en el barrio chino de La Habana y que gira en torno de la pasión de un general cubano por un travestido chino, da el aporte oriental: pequeño pero decisivo para la cultura habanera. El segundo episodio es la vida, muerte y resurrección (poética) de la cantante mulata, Dolores Rondón. En el tercer episodio, Sarduy celebra la lengua española, a través de un gigantesco periplo que se inicia en la España mozárabe y concluye con la entrada de una imagen corrompida de Cristo en La Habana del futuro: una Habana en la que cae la nieve y siniestros helicópteros vigilan todo. Con la libertad de Mário de Andrade (aunque sin conocer naturalmente su obra), Severo Sarduy se instala en el centro de una novelística que asume las formas antes reservadas a lo poético para desconstruir un mundo en que nada es lo que parece ser y todo es, sin embargo, más real (aunque no realista) que los simulacros de la mimesis.

\section{IV.}

El propósito de Guimarães Rosa en Grande Sertāo: Veredas parece más reducido. Aunque su libro es extenso, está fanáticamente concentrado en un área muy específica de la realidad cultural del Brasil y toma de esa área apenas unos caminos. Pero lo que Guimarães Rosa pierde en extensión lo gana en concentración. Su libro es un microcosmos. Si se hubiera publicado en América hispánica en 1956, ¿con qué obras habría sido posible compararlo? Ni Fuentes, ni Vargas Llosa, ni García Márquez, ni Cabrera Infante, ni Sarduy, ni Lezama Lima, habían publicado aún sus novelas. Pero había ya otros autores que estaban ensayando contar de una forma que superase el realismo regionalista sus historias de tierra adentro. Dos años 
después de Grande Sertão: Veredas, el narrador peruano José María Arguedas habría de publicar un libro hermoso: Los ríos profundos. Gran conocedor del quechua y del mundo indígena, Arguedas había reconstruído con una autoridad de la que carecía su compatriota, Ciro Alegría, el mundo real (mitológico tanto como realista) de aquellas poblaciones indígenas del Perú. Pero su libro no resiste la comparación con el de Guimarães Rosa. Lineal, lírico, sutil, carece de esas dimensiones extraordinarias que hacen de la obra de Rosa un summa abismal.

No, el único libro hispanoamericano de aquellos años que se podría colocar junto al de Rosa es Pedro Páramo, del mexicano Juan Rulfo. Aunque Rulfo practica la concentración y la elipsis como formas narrativas básicas, en tanto que Guimarães Rosa usa y abusa de la proliferación y la reiteración, ambos libros son esencialmente semejantes. Hay en ambos una búsqueda de la identidad que se desarrolla tanto en el nivel temático como en el lingüístico. En tanto que el protagonista de Grande Sertão: Veredas, desarrolla en un interminable monólogo la historia de su vida (que es la historia de una pregunta: ¿Hice un pacto con el Diablo?), el protagonista de la novela de Rulfo no se pregunta nada: como una fuerza elemental actúa, para convertir al mundo, su mundo, en un doble de sí mismo. Al morir asesinado por uno de sus hijos bastardos, Pedro Páramo se derrumba como un montón de piedras en el páramo en que su codicia ha convertido al pueblo. Pero si Pedro Páramo no se pregunta, otro de sus hijos, Juan Preciado sí lo hace. Juan viene a Comala a vengar a su madre, de las afrentas que le ha hecho el padre, pero viene sobre todo a descubrir quién es.

La oposición es muy clara: Riobaldo (que es hijo del hombre a quien siempre tomó por padrino), huye de su padre al saber la verdad: se hunde en el sertão, se hace jagunço para descubrir quén es. Juan Preciado huye hacia su padre. Pero los dos movimientos son el mismo. Cualquier lector de Edipo Rey sabe que Edipo huyó de Argos (que él creía su tierra natal) para no cumplir la maldición del oráculo, y que en Tebas (que era su verdadera tierra) mató a un desconocido que era su padre. Hijos que huyen de sus padres, hijos que huyen hacia sus padres, los desiertos de América están llenos de seres desesperados en busca de su identidad.

Las mujeres también buscan. En Pedro Páramo, Susana San Juan tiene una fijación de odio en su padre, Bartolomé, que tal vez la hizo su amante. En Grande Sertão: Veredas, Deodorina/Diadorim busca vengar la muerte de su padre, y en su venganza se fija en la imagen masculina: viste ropas de jagunço, oblitera en ella lo que no sea la sagrada misión. Pero no hay que exagerar los paralelos y los contrastes temáticos. En los dos libros, la naturaleza asiste al espectáculo de seres atormentados por el deseo, por el incesto, por maldiciones que ya no consiguen entender. Pero en tanto que Pedro Páramo está escrito bajo el signo de la muerte (hacia la mitad del libro se descubre que todos los personajes ya están muertos y que los narradores yacen en una tumba de polvo), en Grande Sertão: Veredas hay una esperanza de salvación. Riobaldo cuenta su historia al doctor que no habla 
pero toma notas, y al ir desenvolviendo el hilo de la misma concentra simbólicamente en tres días de evocación y pesquisa todo un tratamiento psicoanalítico. Al final, aunque no hay respuesta se entiende que hay una solución: la pregunta es ya una respuesta. Riobaldo ha llegado al fondo de su búsqueda.

Rulfo sintetiza en su breve novela toda la realidad mexicana. No sólo la revolución de 1910, a la que Pedro Páramo traiciona como traiciona todo en el libro, sino esa realidad fuera de la historia y que mantiene vivo el mundo azteca debajo de las estructuras superficiales del México moderno. El culto de la muerte que los conquistadores españoles no erradicaron sino que enriquecieron con la deslumbrante iconografía masoquística del Calvario y la Pasión, está paradójicamente vivo en Pedro Páramo: es claro que es la vida de ultratumba, la vida de la voz de sus personajes muertos. En Grande Sertão: Veredas, la única voz que se oye directamente, la del narrador Riobaldo, está viva de otra manera. Presa en el mundo cíclico de su monólogo, la voz de Riobaldo desarrolla su discurso pero circularmente: una y otra vez vuelve al momento focal, el centro del laberinto, esa ausencia que es una pregunta: hizo o no un pacto con el Diablo en el desierto. La pregunta sólo es comprensible en el contexto cristiano. Además, sólo es comprensible si se entiende que enmascara otra pregunta que el narrador apenas si se atreve a hacer: ¿es posible desear a otro ser igual a uno? $\mathrm{El}$ angélico Diadorim es el Diablo porque es el Deseo de lo que está prohibido, pero es también el Angel de la Guarda, porque en realidad no está prohibido: sólo lo parece. En realidad (en la realidad de esta ficción), Diadorim/Deodorina no es Diablo ni Angel: es otro ser aún más fundamental. Es el Andrógino: la criatura original que réune en sí los dos sexos, los dos polos, de la realidad.

Por este camino, Grande Sertão: Veredas sale de la órbita de Pedro Páramo (que no admite otra solución para el incesto que la muerte de todos) y se enlaza con el tema central de otro libro de la novela hispanoamericana: Paradiso, del cubano José Lezama Lima, que se publicó exactamente diez años después del de Guimarães Rosa. En Paradiso, Lezama explora muchas cosas pero sobre todo explora una: el origen del deseo homosexual que él encuentra en el mito del Andrógino, el ser que posee ambos sexos y que encuentra en la dualidad de su ser, la unidad de su deseo. Ser que se mira a un espejo y que busca lo mismo, no lo otro, el Andrógino es para Lezama algo más que un prototipo sexual. Es también el prototipo del poeta, como lo hace muy explícito el personaje de Oppiano Licario, Orfeo cubano que rescata para el protagonista, José Cemí, el mensaje de ultratumba que le ha dejado su padre. Pero que es también el taumaturgo que lo inicia en el ritmo secreto que rige la poesía y el mundo.

Busca de la identidad, mediadores órficos, andróginos que tientan como demonios, los temas y prototipos de estas dos novelas son permutables. Un modelo común las une: el aprendizaje, el rito de pasaje. Todas son, en medida más o menos explícita, variantes de un modelo 
narrativo: el bildungsroman. Ya Don Segundo Sombra (con la que tiene semejanzas superficiales Grande Sertão: Veredas) lo había anticipado pero en una forma demasiado lineal. Por su parte, Rulfo, Guimarães Rosa y Lezama Lima construyen complejos laberintos verbales. Lo que nos devuelve a otro aspecto central. Hay en Rulfo, Rosa y Lezama una búsqueda de la identidad que no se manifiesta sólo a nivel temático. En tanto que Rulfo construye su novela por el collage de textos breves, nítidamente recortados, que remiten a una doble visión fundamental-- el diálogo de muertos que preside Juan Preciado, los fragmentos pétreos de la vida de Pedro Páramo, presentados sin explicaciones por un narrador anónimo y omnisapiente--, Grande Sertão: Veredas instaura desde la primera palabra un diálogo polifónico en que la voz del narrador único se desdobla en funciones (narrativa, crítica, dialéctica) que Irlemar Chiampi Cortez ha analizado en un trabajo reciente. Lezama Lima recurre a una narración en tercera persona que a partir de la mitad empieza a romperse para admitir no sólo las visiones del protagonista sino textos literarios incrustados que tal vez sean de su maestro. Tanto en la novela mexicana como en la brasileña o la cubana, la narración lineal desaparece o resulta recargada de dimensiones inesperadas. Por el camino de su discurso narrativo, la búsqueda de la identidad (esta vez, literaria) persiste.

\section{$\mathrm{V}$.}

Once años después de publicado Grande Sertão: Veredas, Gabriel García Márquez habría de publicar el popularísimo Cien años de soledad. La búsqueda de la identidad personal no desaparece aunque es trasladada a la búsqueda de la identidad de toda una estirpe; el tema de la tentación del incesto encuentra en la historia de una familia su habitat natural; hasta la figura del Andrógino reaparece sutilmente en esas parejas contrastadas de Aurelianos y José Arcadios que atraviesan la novela con sus soledades a cuestas: mitades irreconciliables de seres que el destino partió en dos. Si en Grande Sertão: Veredas, como en Macunaíma, hay una piedra mágica, en Cien años de soledad hay un texto mágico: el libro de Melquíades, cuya pérdida y recuperación dan centro invisible al largo hilo narrativo. En Paradiso, el objeto mágico es el ritmo hesicástico que José Cemí descubre en las palabras de Oppiano Licario. Piedra preciosa, talismán, libro mágico, ritmo poético: todos estos objetos aluden a una dimensión de la realidad que no es la que querían instaurar los trabajosos novelistas del realismo regionalista. Esa realidad que se da en México como en Cuba, en Brasil como en Guatemala, en Colombia como en el Río de la Plata (el habitat de Borges, Bioy Casares y Cortázar, no se olvide), es la realidad latinoamericana que esta lectura cruzada y anacrónica de textos ha tratado de evocar. La realidad que los viejos cánones del realismo mimético no puede alcanzar y que estos brasileños, como aquellos mexicanos o cubanos o argentinos o colombianos, han logrado capturar en libros que hoy ya no pertenecen a un país sino al continente entero. 
